\title{
ANÁLISIS SEMÁNTICO-COGNITIVO DEL DISCURSO HUMORÍSTICO EN EL TEXTO MULTIMODAL DE LAS VIÑETAS DE FORGES
}

\author{
MARTA AgÜERo GUERRA \\ Universidad de Salamanca - The University of Iowa \\ marta-agueroguerra@uiowa.edu
}

Resumen

Partiendo de la semántica y la lingüística cognitiva, la Teoría General del Humor Verbal (Attardo y Raskin, 1991; Attardo, 1991, 2001 y 2006), deudora de la teoría de la incongruencia (Kant, 1790; Schopenhauer, 1891[1818]), sostiene que los mecanismos de comprensión del humor están basados en la resolución, parcial o total, de una incongruencia producida por la alternancia de marcos cognitivos (scripts) incompatibles. En este estudio se demuestra que la TGHV es perfectamente aplicable al humor gráfico contemporáneo como género multimodal y sirve de base para el análisis de un corpus representativo de viñetas de Forges, clasificadas según el modelo 3 WD de apreciación del humor (Ruch, 1992; Hempelmann y Ruch, 2005). El análisis evidencia que Forges emplea, junto a la ironía y la metáfora, diversos mecanismos complementarios en viñetas donde palabra e imagen convergen en una identidad de lectura recíproca para criticar la realidad social y política actual.

PALABRAS CLAVE: Humor gráfico, Teoría General del Humor Verbal, Test 3 WD, Lingüística cognitiva.

\begin{abstract}
Taking Semantics and Cognitive Linguistics as a point of departure, the General Theory of Verbal Humor (Attardo and Raskin, 1991; Attardo, 1991, 2001 and 2006), heir to the incongruity theory (Kant, 1790; Schopenhauer, 1891[1818]), states that humor comprehension mechanisms are based on the partial or complete resolution of an incongruity produced by the opposition of incompatible scripts. This article demonstrates that the GTVH can be perfectly applied to contemporary graphic humor as a multimodal genre and serves as the basis for the analysis of a representative corpus of cartoons by Forges that has been classified according to the 3 WD test of humor appreciation (Ruch, 1992; Hempelmann and Ruch, 2005). The analysis shows that, together with irony and metaphor, Forges uses a variety of complementary mechanisms in cartoons containing visual and verbal elements that work together and encourage an implicit evaluation of the social and political contemporary reality.
\end{abstract}

KEY WORDS: Graphic humour, General Theory of Verbal Humour, 3 WD Test, Cognitive Linguistics.

\section{Introducción}

El humor es un fenómeno cuyo estudio se aborda, en la actualidad, desde una perspectiva multidisciplinar, en campos científicos tan diversos como la antropología, la 
sociología, la medicina o la lingüística. Es un concepto elusivo, difícil de definir, si se tienen en cuenta los diversos factores que entran en juego en la producción y comprensión de un texto humorístico.

En este artículo se analizará exclusivamente el humor gráfico en la viñeta de prensa actual, concebida como una unidad narrativa espacio-temporal que codifica el discurso humorístico (verbal y/o visual) de un determinado autor. Su estudio se abordará partiendo de un amplio corpus de 372 viñetas, creadas por Antonio Fraguas ${ }^{1}$, Forges ${ }^{2}$ y publicadas en las páginas de opinión del diario El País entre el 1 de febrero de 2010 y el 28 de febrero de 2011. La poética del cómic en la prensa permite distinguir tres formatos bien definidos en los que el autor refleja su visión crítica de la realidad: la viñeta única (caricatura o cartoon), la tira cómica y la historieta seriada.

La viñeta editorial se publica en las páginas de opinión de los periódicos con una clara función ideológica. Su propósito es cuestionar con lucidez las actitudes sociales y evaluar, de forma implícita (irónica), una única visión de la realidad (El Refaie, 2005).

\footnotetext{
${ }^{1}$ Quiero expresar mi agradecimiento a Antonio Fraguas (Forges) por su generosidad al autorizar la reproducción de las viñetas incluidas en este artículo. Mi trabajo es un humilde tributo a la obra de un excepcional creador de la viñeta de opinión, cuya visión irónica de la realidad es un inapreciable testimonio diario que contribuye a cuestionar las actitudes y comportamientos de nuestra sociedad con una inteligencia analítica que cautiva al lector por su ingenio y su humor mordaz.

${ }^{2}$ Antonio Fraguas de Pablo, conocido como Forges, su apellido en catalán, nace en Madrid en 1942. Después de trabajar durante años en televisión, publica su primer dibujo en 1964 en el diario Pueblo. Ha trabajado como viñetista en diferentes revistas de humor como Hermano Lobo, Por Favor o El Jueves y en periódicos como Diario 16 o El Mundo. Además, ha ilustrado diferentes libros, ha escrito una novela, Doce de Babilonia, y ha publicado libros sobre la historia de España en forma de cómic, Historia Forgesporánea o Los Forrenta Años. Desde 1995 colabora a diario en El País. Es un creador de personajes de repertorio caricaturizados (i.e. funcionarios antipáticos, becarios explotados, matrimonios aburridos o mujeres familiares y trabajadoras) que comparten unos rasgos comunes (grandes narices y ojos, escasez de pelo, cuerpos flexibles...). Su ingenio consiste en condensar en el pequeño espacio de sus viñetas dibujos sencillos que representan escenas cotidianas con mensajes lingüísticos marcados por un gusto desmesurado por los neologismos (Galán Rodríguez, 1994). Forges es un creador lingüístico que juega con el lenguaje popular y los sonidos, como se aprecia en sus conocidos forgendros (gensanta, chasgracias, parejólogo, aeropuerting...). El humor de Forges es un humor inteligente, de su tiempo, "comprometido con la sonrisa de los seres humanos a través de poner en solfa la injusticia, la insolidaridad y la estupidez del poder" (entrevista al autor en El Diario Montañés, 16 de julio de 2006, disponible en <http://www.eldiariomontanes.es/prensa/20060716/sociedad/antoniofraguas-forges-dibujante_200607160034.html>). De ahí que sus técnicas más frecuentes sean la ironía, la paradoja y la hipérbole. No se trata de un humor cruel, sino comprensivo, realizado con ternura, pero que no deja de ofrecer una crítica mordaz e irónica de la realidad social y política actual. Sus viñetas son el escaparate en el que ofrece a los demás su manera de ver la vida $(<\mathrm{http} / / /$ www.forges.com $>/$ $<$ http://www.elpais.com/vineta/>).
} 
Algunos humoristas gráficos prefieren un formato de viñeta exclusivamente visual, mientras que otros prefieren un formato escripto-icónico, que combina narración visual (i.e. aplica los recursos de composición gráfica, como son el encuadre, los ángulos de visión, el color, el estilo del trazo o el gestuario de los personajes) y narración verbal (diálogo, onomatopeya, globos o cartelas).

En las viñetas exclusivamente visuales, el mensaje humorístico suele coincidir con una metáfora visual que, por sí misma, evoca múltiples significados (Fig. 1). La Teoría de la Metáfora Conceptual (Conceptual Metaphor Theory), iniciada por Lakoff y Johnson, explica este tipo de metáforas como representaciones visuales de un pensamiento metafórico (Lakoff y Johnson, 1980). En este tipo de viñetas, el dominio origen (source domain) y el dominio destino (target domain) de la metáfora se encuentran en la misma modalidad (Ortiz Díaz-Guerra, 2010). Es tarea del lector identificar por medio del contexto pictográfico cuál es el segundo término al que alude la metáfora. No obstante, es fundamental que el lector conozca el contexto informativo en el que se publica la viñeta para comprender su significado: "it would be important to study the meaning of cartoons in relation to a whole page or even a complete issue of a newspaper" (El Refaie, 2003: 92). La metáfora visual de la Figura 1 es de difícil comprensión si no se conoce el co-texto verbal que acompañaba a la viñeta en el diario El Pais en febrero de 2011. En aquel momento, los ciudadanos de los países del norte de África habían iniciado una revolución exigiendo mayor democracia y mejores condiciones de vida. La publicación de esta viñeta coincidió con una oleada de protestas en Egipto que reclamaba el final de la era Mubarack y la dimisión en bloque de la cúpula de su partido.

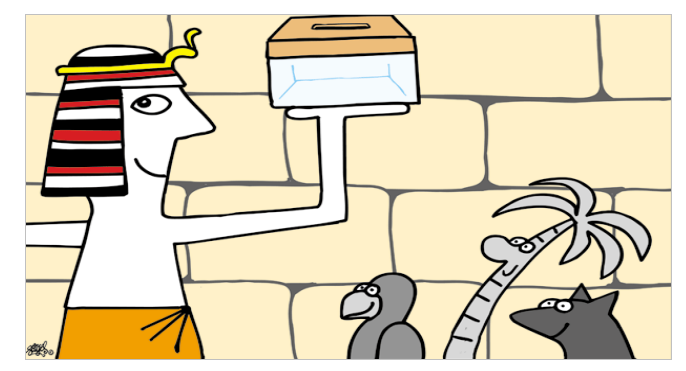

Fig.1. El País, 5 febrero 2011. Reproducción autorizada por Forges

En el segundo tipo de viñetas multimodales se produce una fusión o interacción entre imagen y palabra. El término multimodalidad ha sido acuñado recientemente en el ámbito de la comunicación audiovisual y de la narratología para referirse a formas textuales en las que existe más de un código semiótico, ya sea texto, imagen, gesto o sonido 
(Kress y van Leuween, 2006 [1996]). En el proceso de interpretación, el lector debe primero asumir la presunción óptima de relevancia, con el fin de restringir el número de inferencias posibles y así poder captar el mensaje humorístico de la viñeta (Sperber y Wilson, 1986). No basta, sin embargo, con la comprensión del código lingüístico sino que es preciso descifrar el mensaje codificado que resulta de la interacción entre elementos simbólicos (palabras) y elementos icónicos (imágenes).

Barthes (1977) analizó la relación entre imagen y palabra y estudió el papel que ambos recursos semióticos desempeñaban en la transmisión del mensaje. Distinguía dos formas de representación del lenguaje: función de relevo y función de anclaje. Cuando en una viñeta existe una función de relevo, es la imagen la que ayuda a interpretar el mensaje lingüístico (Fig. 2). Los elementos lingüísticos y analógicos están en relación complementaria, en muchos casos contradictoria, cuando se les atribuye significado irónico. Por el contrario, en la función de anclaje, es el mensaje lingüístico el que da sentido al contenido de la imagen, subrayando asimismo su marcado valor irónico (Fig. 3). En la Figura 2 es necesario analizar el dibujo para poder comprender el chiste, ya que las palabras emprendedor e ilusionado no se corresponden con la expresión facial y la actitud despreocupada del personaje de la viñeta. Por el contrario, en la Figura 3, el cartucho Tesoro Público en la puerta confiere sentido a la gestualidad del personaje y a su deseo de conseguir la llave en el interior de la urna (tesoro privado).

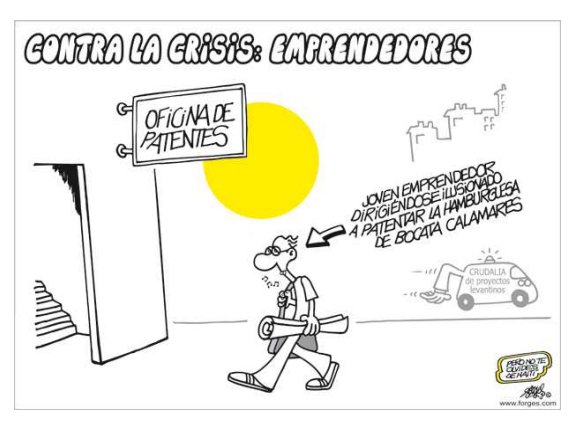

Fig. 2. El País, 15 octubre 2010. Reproducción autorizada por Forges

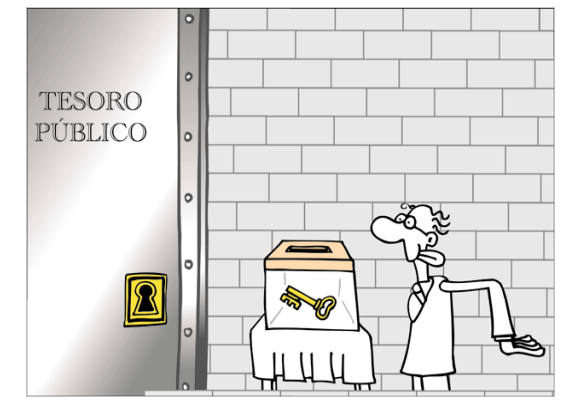

Fig. 3. El País, 7 febrero 2011. Reproducción autorizada por Forges

Son numerosas las investigaciones que abordan en la actualidad el análisis del texto multimodal. Desde que Halliday sentara las bases de la Lingüística Sistémico-Funcional (1985), el interés de los lingüistas por explorar la interacción del lenguaje con otros recursos semióticos ha crecido considerablemente (O’Halloran, 2011). Los estudios más novedosos en este terreno han partido de la semiótica social (Kress y van Leeuwen, 2001 
y 2006 [1996]), desde donde se postula la necesidad de desarrollar una gramática visual que ayude a interpretar los patrones de significado expresados en las imágenes. Otros estudios han abordado la multimodalidad en los libros ilustrados (picture books) vinculada a un tema de creciente interés: la alfabetización visual (Moya Guijarro y Pinar Sanz, 2009). Elizabeth El Refaie (2003, 2009a, 2010) ha analizado los distintos factores que entran en juego en la comprensión de textos humorísticos multimodales (i.e. el conocimiento del género, el contexto, la edad o el propio formato de presentación de las viñetas) $)^{3}$.

El objetivo de este artículo consistirá en describir los recursos que Forges emplea en sus viñetas de opinión (editorial cartoons) para conseguir un efecto cómico partiendo de un análisis semántico-cognitivo. Se analizará el mensaje lingüístico de sus viñetas a partir de la Teoría General del Humor Verbal (TGHV) (Attardo y Raskin, 1991; Attardo, 1991, 2001 y 2006) y el modelo 3 WD (3 Witz Dimensionen) de apreciación del humor (Ruch, 1992; Hempelmann y Ruch, 2005). Una vez delimitado el campo de estudio a la viñeta humorística de prensa, o viñeta editorial, en sus dos formatos (monomodal y multimodal), se identificará, a continuación, el marco teórico en el que se inscribe este análisis junto a una breve referencia a las teorías filosóficas del humor, precursoras de los enfoques actuales. Por último, se procederá a analizar las viñetas seleccionadas y los resultados que arroje esta investigación con el fin de comprender los mecanismos que utiliza Forges para transmitir su crítica irónica de la realidad política y social.

\section{Marco teórico: Teorías del humor}

Han sido numerosas las teorías que han tratado de explicar desde diversas disciplinas qué mecanismos desencadenan la risa. Las primeras teorías del humor se formularon en el campo de la filosofía. La más antigua es la Teoría de la Superioridad (Hobbes, 1994 [1668]; Bergson, 1911 [1899]), que afirma que nos reímos de los demás cuando los vemos en una situación de desventaja, i.e. cuando detectamos algún defecto ajeno, alguien comete algún error o sufre algún contratiempo. Freud (1991 [1905]) y Spencer (1911) parten de la noción de risa como correctivo social que pone en tela de juicio las

\footnotetext{
${ }^{3}$ Forceville y Urios Aparisi (2009) continúan investigando los procesos cognitivos que entran en juego en la interpretación de las metáforas multimodales y proponen un enfoque que aúne lingüística cognitiva y semiótica. María Jesús Ortiz (2010: 122) aboga, en cambio, por una teoría integrada de la metáfora visual, dado que la metáfora es "un proceso cognitivo que puede manifestarse tanto de modo verbal como de modo no verbal".
} 
normas impuestas por la sociedad para desarrollar la Teoría de la Liberación de Tensión. La risa es el resultado del sentimiento de alivio que nos produce superar una situación de restricción, dando lugar a un incremento de la energía nerviosa que se manifiesta en forma de risa, como ocurre, por ejemplo, cuando oímos algo que no es políticamente correcto. Por último, la tercera teoría filosófica, la Teoría de la Incongruencia, es en la que se basan la mayoría de las investigaciones que se están realizando en la actualidad y, por lo tanto, es sobre la que se asientan las teorías utilizadas para llevar a cabo el análisis en este trabajo. Esta teoría, articulada en los siglos XVIII y XIX, y cuyos máximos exponentes fueron Kant (1790) y Schopenhauer (1891[1818]), defiende que la risa se produce como resultado de una disonancia entre lo que es esperable en una determinada situación y lo que realmente ocurre. Como se explicará más adelante, esta idea de disonancia es clave para la percepción del humor.

Tomando como punto de partida la teoría de la incongruencia, los estudios del humor en español se han afianzado notablemente en los últimos años gracias a interesantes contribuciones que lo han abordado desde una perspectiva lingüística. Buen ejemplo de ello son las publicaciones de Leonor Ruiz Gurillo (2012), Ana María Vigara Tauste (2004) o las investigaciones que se impulsan desde el grupo GRIALE en la Universidad de Alicante. La pragmática ha estudiado también este fenómeno, entendiéndolo como una forma de metacomunicación:

Humor is an implicit form of communication, which deliberately leaves something implied and requires a greater level of cooperation on the part of the viewer/reader than the processing of a piece of ordinary information. Because of this, any theory of humor must also explore the pragmatics of humor appreciation (El Refaie, 2009b: $82)$.

Los estudios pragmáticos se han centrado en las teorías que se desarrollaron durante los años setenta y ochenta del siglo XX para explicar el proceso comunicativo: el Principio de Cooperación de Grice (1975), el Principio de Cortesía de Leech (1983) y la Teoría de la Relevancia de Sperber y Wilson (1986). Esta última considera que la clave del discurso humorístico reside en la búsqueda de relevancia óptima que realiza el destinatario del mensaje en cualquier intercambio comunicativo. A pesar de que no se trata de una teoría diseñada específicamente para el análisis del humor, lingüistas como Francisco Yus (2003), entre otros, defienden su utilización para interpretar las manifestaciones humorísticas y su aplicabilidad a los textos verbo-icónicos (Yus, 1995). Yus señala que la búsqueda de relevancia no se produce exclusivamente por parte del receptor, sino también por parte del emisor. El humorista construye sus chistes prediciendo el tipo de presuposición que va a escoger su interlocutor y asumiendo que los interpretará en dos fases: primero seleccionará una interpretación accesible por medio del principio de 
relevancia y más tarde la invalidará, sustituyéndola por una más adecuada. De este modo, Yus enlaza la Teoría de la Relevancia con estudios teóricos posteriores y propone el análisis de los procesos cognitivos que realizan los emisores para codificar el mensaje humorístico.

La pragmática no ha sido la única disciplina lingüística que ha investigado el concepto de humor; también desde la semántica y desde la lingüística cognitiva se han aportado interesantes teorías sobre este tema, como la que se ha tomado para este análisis, que se encuentra a medio camino entre estas dos áreas: la Teoría General del Humor Verbal (Attardo y Raskin, 1991; Attardo, 1991, 2001 y 2006). Esta elección se ve justificada si partimos de la idea de que no se puede concebir la percepción y producción del humor sin atender al significado de los enunciados o a los procesos cognitivos que se producen en diferentes partes de nuestro cerebro a la hora de descifrar el mensaje humorístico.

Las teorías cognitivas sostienen que la percepción de una incongruencia es la base de la mayor parte de nuestras experiencias humorísticas. Entre los teóricos que han investigado el humor desde un punto de vista cognitivo merecen especial atención Schank y Abelson (1977), a quienes debemos el concepto de marco cognitivo o script que posteriormente sentó las bases de las teorías que han fundamentado mi investigación. Estos autores apoyan la tesis de Lakoff (1987) sobre la organización de nuestro conocimiento mediante estructuras llamadas "modelos cognitivos idealizados". Los marcos cognitivos (scripts), en términos de representación psíquica, son entidades de organización de la memoria episódica, construidos alrededor de experiencias reales; es decir, un script es una estructura cognitiva interiorizada que nos proporciona información sobre cómo está estructurada una entidad determinada (palabra, situación, etc.), cuáles son sus partes y qué relaciones tienen con otras entidades.

Partiendo de este concepto de marco cognitivo (script) y de la Teoría de la Incongruencia, Raskin desarrolla la Teoría Semántica de Esquemas, que postula que cualquier texto humorístico debe contener dos marcos cognitivos (scripts) que se oponen entre sí en tres tipos generales de relaciones: (1) real / irreal, (2) normal / no normal, (3) posible / imposible (Raskin, 1985). Estas, a su vez, pueden dividirse en subcategorías binarias más concretas, como vemos en este ejemplo, donde se oponen los marcos cognitivos (scripts) doctor / amante y sexo / no sexo:

(1)

- “'Está el doctor en casa?’ pregunta el paciente con un hilo de voz provocado por el catarro.

- 'No', responde la joven y bella esposa del doctor. 'Pasa'” (Raskin, 1985: 32). 
A pesar de la importante contribución que supuso la Teoría Semántica de Esquemas para comprender el texto humorístico, algunas investigaciones posteriores la han refutado, puesto que no se trata de una teoría aplicable al humor en general, sino solo al humor verbal y, en concreto, al chiste. Sin embargo, esta teoría es precursora de la Teoría General del Humor Verbal (Attardo y Raskin, 1991; Attardo, 1991, 2001 y 2006), en la que se ha basado el presente análisis.

La Teoría General del Humor Verbal (en adelante, TGHV) integra la Teoría Semántica de Esquemas (Raskin, 1985) con los cinco niveles de representación del humor verbal de Attardo, creando un modelo jerárquico dividido en seis parámetros que ayudan a resolver la incongruencia y comprender los textos humorísticos: (1) la oposición de los marcos cognitivos, (2) la situación desencadenante del chiste, (3) el mecanismo lógico que crea la oposición, (4) el objetivo o blanco del texto, (5) la estrategia narrativa y (6) el lenguaje utilizado:

1. La oposición de marcos cognitivos (scripts) (Script Opposition o SO): el parámetro heredado de la Teoría Semántica de Esquemas y requisito indispensable para la producción y comprensión del humor.

2. El mecanismo lógico (Logical Mechanism o LM): la manera en que dos marcos cognitivos (scripts) se relacionan (ambigüedad, analogía, contradicción, exageración, yuxtaposición, etc.)

3. La situación (Situation o SI): el contexto del chiste; incluye los personajes, las actividades, objetos, instrumentos que rodean al blanco del chiste

4. El blanco (Target o TA): el objetivo del chiste, que suele coincidir con personajes estereotipados social o políticamente.

5. La estrategia narrativa (Narrative Strategy o NS): la organización narrativa del chiste (i.e. su género).

6. El lenguaje (Language o $L A$ ): la información necesaria para la verbalización de un texto como, por ejemplo, las elecciones fonéticas, fonológicas, morfológicas, léxicas, semánticas y pragmáticas que realiza el emisor.

Algunos defensores de la TGHV han añadido posteriormente detalles a estos parámetros para ampliar su aplicabilidad a todo tipo de textos humorísticos. Leonor Ruiz Gurillo (2012: 41), en su interesante estudio de la lingüística del humor en español, completa la TGHV y amplía algunos parámetros. Añade relaciones sintagmáticas o razonamientos a los mecanismos lógicos de Attardo y Raskin y explicita el parámetro de la estrategia narrativa para que incluya el análisis del registro y del género textual.

A diferencia de la Teoría Semántica de Esquemas, que solo era aplicable al chiste, la Teoría General del Humor Verbal abarca todos los tipos de humor verbal, ya que la 
introducción de estos cinco nuevos parámetros es fundamental para distinguir entre los distintos tipos de textos humorísticos. Además, los parámetros establecidos en esta teoría son perfectamente aplicables al análisis del humor gráfico como género multimodal que integra elementos verbales e icónicos (Forceville, 2006):

(2)

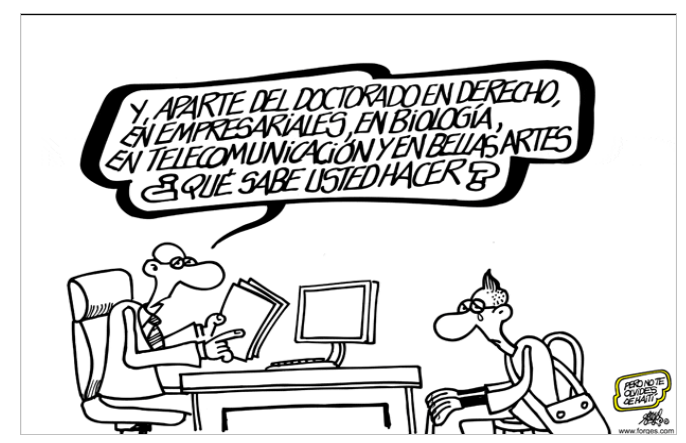

Fig. 4. El País, 2 noviembre 2010. Reproducción autorizada por Forges

1. Oposición de marcos cognitivos (SO): Formación / no formación: tener un buen nivel educativo es una ventaja para encontrar trabajo / tener diferentes doctorados equivale a no saber hacer nada.

2. Mecanismo lógico (LM): Exageración (de la poca importancia que se le dan a los doctorados) y contradicción (cuantos más méritos se tiene, más difícil es conseguir un trabajo).

3. Situación (SI): Un joven con cinco doctorados en una entrevista de trabajo.

4. Blanco (TA): Empresas/doctores cualificados.

5. Estrategia narrativa (NS): Viñeta con una escena y globo.

6. Lenguaje (LA): Lenguaje hiperbólico (amplificación por repetición) en contradicción con la imagen.

El mensaje humorístico de las viñetas multimodales se encuentra codificado en la interacción de imagen y palabra. Se trata de una relación semántica (i.e.: ambos elementos construyen el significado en una relación complementaria), dado que la comprensión del texto no sería completa sin uno de los dos recursos semióticos. Por esta razón, la TGHV es perfectamente aplicable al estudio y comprensión de los dos códigos semióticos. "Although Attardo and Raskin's GTVH was developed to explain verbal jokes, there is no reason why it cannot be applied to cartoon humor as well" (El Refaie, 2009b: 81). En efecto, al aplicar teorías lingüísticas al estudio de textos multimodales, hay que 
tener en cuenta que cada género tiene sus propios modos de construcción de significado. En el caso de las viñetas multimodales, las relaciones plásticas y semánticas que se establecen en el marco de la viñeta son relevantes para un estudio de estas características (Kress y van Leeuwen, 2001). En la Figura 4, la mayoría de las interpretaciones proporcionadas en el análisis de los distintos parámetros no serían apreciables sin el componente visual.

Algunos estudios posteriores a la Teoría General del Humor Verbal han investigado, además, el nivel de resolución de la incongruencia necesario para comprender un texto humorístico. Hempelmann y Ruch (Ruch, 1992; Hempelmann y Ruch, 2005) proponen una taxonomía a partir del Test 3 WD (3 Witz Dimensionen), un modelo para la apreciación del humor que distingue tres categorías relacionadas con el nivel de incongruencia: (1) humor que resuelve la incongruencia (INC-RES), (2) humor absurdo o sin sentido que apenas resuelve la incongruencia (NON) y (3) humor de contenido sexual (SEX). Partiendo de un análisis empírico de un corpus de chistes, Hempelmann y Ruch (2005) llegan a la conclusión de que la incongruencia que se produce en los textos humorísticos siempre se resuelve de una manera parcial, por lo que INC-RES y NON son dos extremos de un continuo de procesos cognitivos. INC-RES es el extremo más cercano a la resolución completa, mientras que NON es el extremo más cercano a una falta de resolución. En el corpus que ha servido de base para la elaboración de este artículo, se han identificado aquellas viñetas de Forges que resuelven casi por completo la incongruencia (Fig. 5.) y las que apenas la resuelven (Fig. 6.). No se han identificado, en el corpus seleccionado, viñetas de contenido sexual.

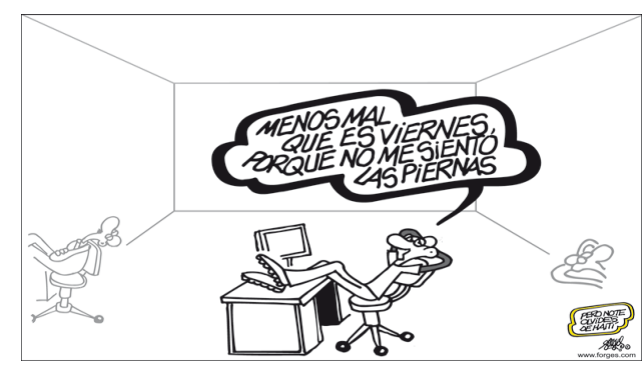

Fig. 5. El País, 19 noviembre 2010. Reproducción autorizada por Forges

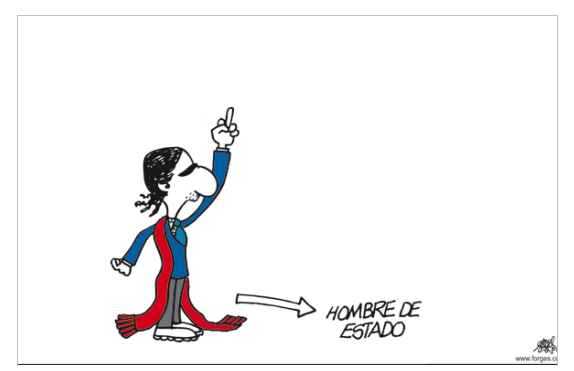

Fig. 6. El País, 19 febrero 2010. Reproducción autorizada por Forges

Además de la TGHV y del Test 3 WD se han tenido en cuenta aportaciones posteriores que han sido precursoras en la investigación del humor gráfico. John C. Paolillo (1998) aplica la Teoría General del Humor Verbal al análisis de un corpus de ochocien- 
tas viñetas de la serie Far Side Cartoons de Gary Larson para identificar características comunes. Paolillo crea una primera lista de quince mecanismos lógicos (o maneras en las que se relacionan dos marcos cognitivos) aplicables al análisis de viñetas. Posteriormente, Attardo, Hempelmann y Di Maio (2002: 9) la amplían y crean una taxonomía de mecanismos lógicos (LMs), que se ha utilizado para analizar las viñetas editoriales de Forges. Hempelmann y Ruch (2005) llegan a la conclusión de que, de los seis parámetros de la TGHV, solamente cuatro son relevantes para el análisis de viñetas: (1) la oposición de marcos cognitivos (scripts) (SO), (2) los mecanismos lógicos (LMs), (3) la estrategia narrativa (NS) y (4) el blanco (TA). No consideran relevantes el análisis del lenguaje (LA) y de la situación (SI), ya que es difícil encontrar elementos en común entre estos parámetros. Por último, la investigación más reciente, que ha servido de base para realizar una primera división del corpus seleccionado de viñetas de Forges, es la de Samson (2008). En su estudio, Samson relaciona el proceso de resolución de la incongruencia con diferentes regiones del cerebro y ofrece una distinción entre tres tipos de humor gráfico que difieren en base a sus mecanismos lógicos:

1. Viñetas visuales (PUNs): un elemento visual activa por sí solo dos marcos cognitivos (scripts) que son incongruentes entre sí (Fig. 7).

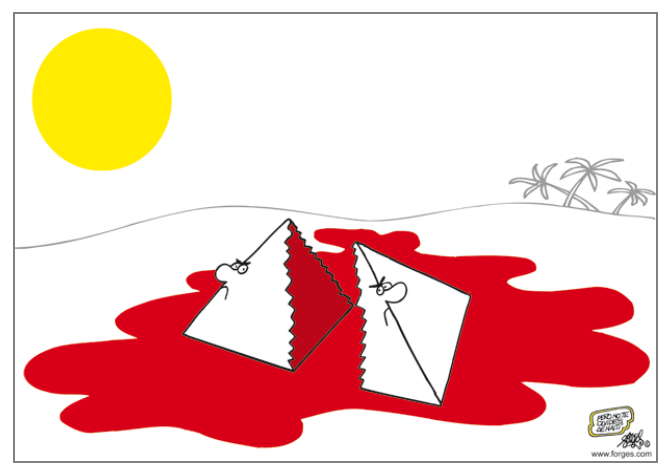

Fig. 7. El País, 4 febrero 2011. Reproducción autorizada por Forges

2. Viñetas semánticas (SEMs): la incongruencia es el resultado de la oposición de dos marcos cognitivos (scripts) basados en aspectos semánticos (Fig. 8). 


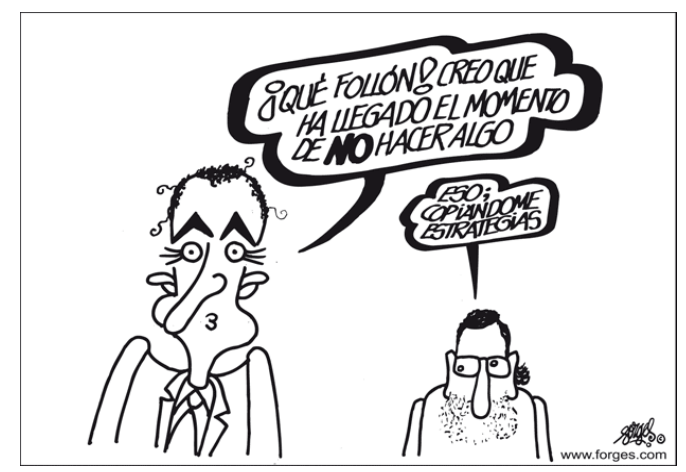

Fig. 8. El País, 6 febrero 2010. Reproducción autorizada por Forges

3. Viñetas de falsa ambigüedad (TOMs: Theory of Mind): requieren la atribución de estados mentales falsos a los personajes para entender el chiste. En ellas un personaje no se da cuenta de algo que es obvio en la viñeta (Fig. 9).

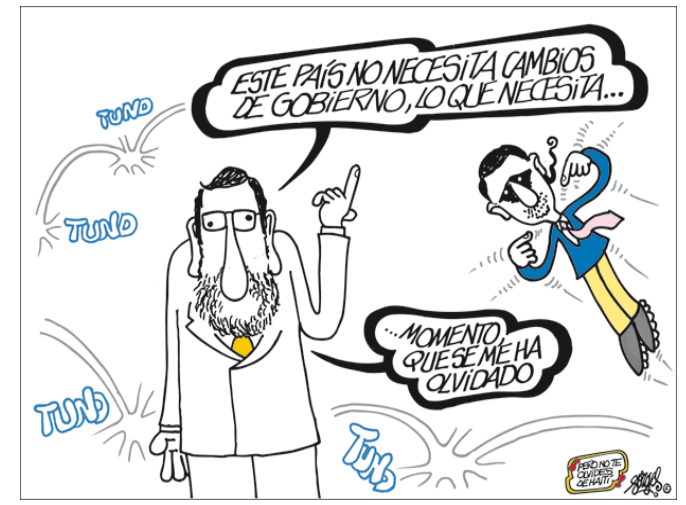

Fig. 9. El País, 21 octubre 2010. Reproducción autorizada por Forges

\section{Método}

En este artículo se ha aplicado la Teoría General del Humor Verbal y el Test 3 WD a un corpus de 372 viñetas de Forges publicadas en el periódico El País entre el 1 de febrero de 2010 y el 28 de febrero de 2011. El corpus seleccionado está compuesto por 89 viñetas de contenido político y 283 viñetas de contenido social. Su análisis está basado en las investigaciones recientes sobre humor gráfico: (1) la clasificación de viñetas realizada por Samson (PUN, SEM y TOM), (2) los parámetros que Hempelmann y Ruch distinguen como relevantes (SO, LM, NS y TA), (3) los mecanismos lógicos generales 
descubiertos por Hempelmann, Attardo y Di Maio, y (4) la división de las relaciones entre marcos cognitivos (scripts) en subcategorías binarias.

El procedimiento que se ha seguido para el análisis de las viñetas de Forges se ha desarrollado en tres fases: (1) división de las viñetas en función de su contenido político y contenido social, (2) análisis pormenorizado de cada grupo de viñetas, y (3) análisis individual de cada viñeta según los cuatro parámetros de la TGHV que son relevantes (SO, LM, NS y TA), en orden jerarquizado, subdividiendo las viñetas en INC-RES y NON y en subapartados cuando ha sido necesario, como en el caso de los mecanismos lógicos, donde era oportuno distinguir entre PUNs, SEMs y TOMs:

(3)

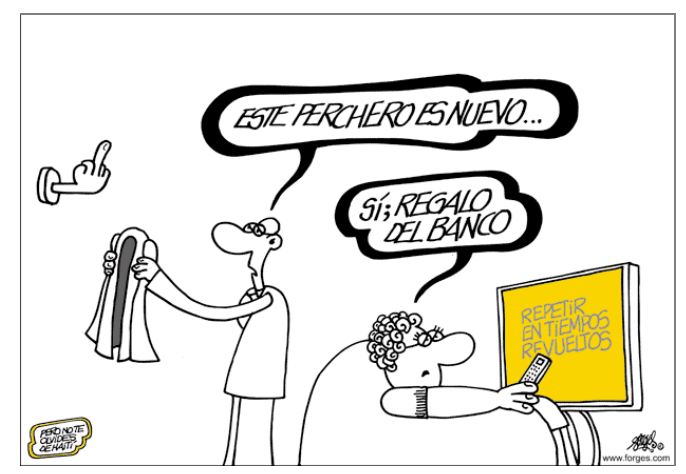

Fig. 10. El País, 3 noviembre 2010. Reproducción autorizada por Forges

1. Contenido social o político: viñeta de contenido social que aborda un tema de interés general: estrategias de captación de clientes con el reclamo de regalos de escasa utilidad.

2. INC-RES o NON: viñeta INC-RES; el remate del chiste ayuda al lector a resolver la incongruencia gracias a la analogía del perchero con el gesto provocador de la peineta (dedo corazón levantado).

3. PUN, SEM, o TOM: viñeta semántica; la incongruencia es el resultado de la oposición de dos marcos cognitivos basados en aspectos semánticos: el banco concede préstamos / el banco no ofrece nada (engaña a los ahorradores); el banco capta el dinero de sus clientes / el banco se queda con su dinero (prácticas fraudulentas).

4. Oposición de marcos cognitivos: la oposición presentada es dinero / no dinero.

5. Mecanismos lógicos: se utiliza la analogía para asociar el perchero, el regalo del banco, con el gesto provocador de la peineta, que revela la actitud de menosprecio de las propias entidades bancarias hacia sus ahorradores. 
6. Estrategia narrativa: Se trata de una viñeta de una sola escena con globos de diálogo y una apoyatura (pantalla de televisión).

7. Blancos u objetivos: crítica a las entidades bancarias.

\section{Análisis y resultados}

\subsection{Viñetas de contenido político}

\subsubsection{Oposición de marcos cognitivos}

Entre las viñetas que resuelven casi por completo la incongruencia (INC-RES), los tipos de oposiciones que más se repiten son: verdad / mentira (4), dinero / no dinero (4), poder / no poder (4), esfuerzo / no esfuerzo (4) (Fig. 11) y voto / no voto (3). En las viñetas políticas que apenas resuelven la incongruencia (NON), este parámetro no es relevante (no se repite).

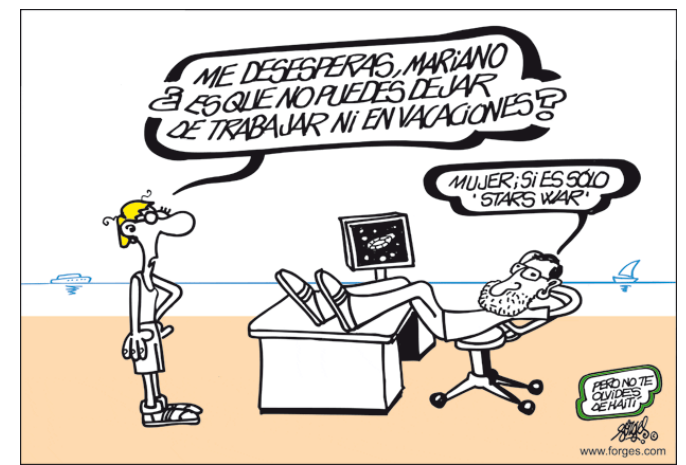

Fig. 11. El País, 17 agosto 2010. Reproducción autorizada por Forges

\subsubsection{Mecanismos lógicos}

Como se aprecia en la tabla que se presenta a continuación (Fig. 12), no se ha encontrado en este corpus de viñetas de contenido político ninguna viñeta visual (PUN) y solo se han identificado dos viñetas de falsa ambigüedad (TOM) en el grupo de las que resuelven casi completamente la incongruencia (INC-RES) (Fig. 9). 


\begin{tabular}{|c|c|c|c|c|c|c|}
\hline \multicolumn{4}{|l|}{ INC-RES } & \multicolumn{3}{|c|}{ NON } \\
\hline LMs & PUN & SEM & TOM & PUN & SEM & TOM \\
\hline Ambigüedad & & 9 & & & & \\
\hline Analogía & & 25 & & & 2 & \\
\hline Contradicción & & 18 & & & 2 & \\
\hline Exageración & & 15 & & & 1 & \\
\hline Cambio de roles & & 1 & & & & \\
\hline Juego de palabras & & 2 & & & & \\
\hline Yuxtaposición & & 8 & & & & \\
\hline Razonamiento desde premisa falta & & 1 & & & & \\
\hline Roles paralelos & & 1 & & & & \\
\hline Error obvio & & & 2 & & & \\
\hline Sin LMs & & & & & 4 & \\
\hline
\end{tabular}

Fig. 12. Tabla de mecanismos lógicos en viñetas de contenido político

Las demás viñetas son semánticas (SEM) y los mecanismos lógicos más utilizados por Forges son analogía (25), contradicción (18) y exageración (15) en las viñetas que resuelven casi completamente la incongruencia (INC-RES). En la Figura 13, Forges establece una clara analogía entre dos políticos europeos y la relación imposible que mantienen los personajes (Don Juan Tenorio y doña Inés) en el drama romántico de José Zorrilla.

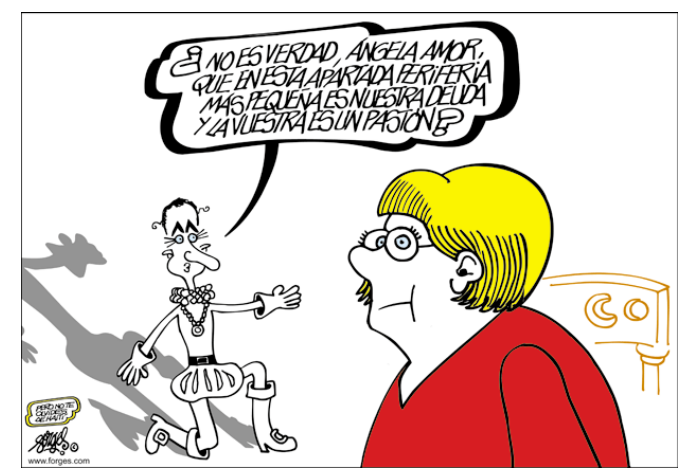

Fig. 13. El País, 3 febrero 2011. Reproducción autorizada por Forges

Sin embargo, en las viñetas que apenas resuelven la incongruencia (NON), la mayoría contiene mecanismos lógicos no definibles. Se trata de viñetas en las que la imagen no es relevante y el mensaje es transmitido exclusivamente por el texto, como se aprecia en la Figura 14. 


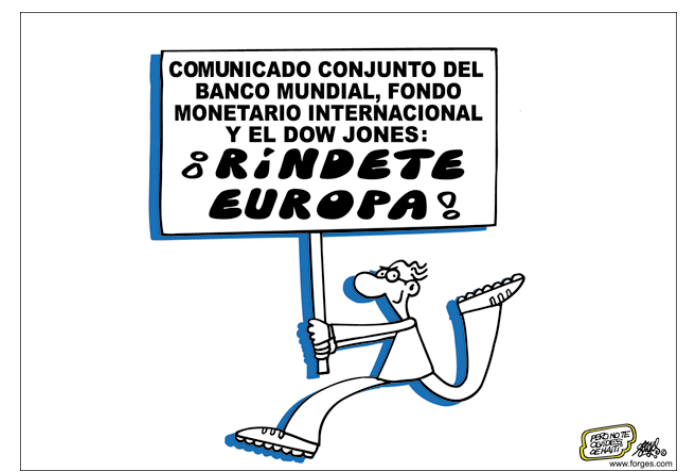

Fig. 14. El País, 27 octubre 2010. Reproducción autorizada por Forges

\subsubsection{Estrategias narrativas}

Como se observa en la tabla (Fig. 15), en las viñetas que resuelven la incongruencia (INC-RES), la estrategia narrativa más utilizada es la de viñetas de una escena con globos $(55)^{4}$, mientras que en las viñetas que apenas la resuelven $(\mathrm{NON})$, la estrategia narrativa más utilizada es la de viñetas de una escena con apoyaturas verbales $(6)^{5}$ (Fig. 14).

\begin{tabular}{|l|c|c|}
\hline \multicolumn{2}{|c|}{ ESTRATEGIAS NARRATIVAS } \\
\hline & INC-RES & NON \\
\hline 1 escena con globlos & 55 & 2 \\
\hline 1 escena con apoyaturas & 4 & 6 \\
\hline 1 escena con globos más apoyaturas & & 1 \\
\hline 1 escena con título & 8 & \\
\hline 1 escena con título más globos & 6 & \\
\hline 1 escena con título más apoyaturas & 5 & \\
\hline 2 escenas con globos & 1 & \\
\hline 2 escenas más títulos & 1 & \\
\hline
\end{tabular}

Fig. 15. Tabla de estrategias narrativas en viñetas de contenido político

\footnotetext{
${ }^{4}$ Forma gráfica que introduce el diálogo o los pensamientos de los personajes y que consiste en un cuerpo circular u ovalado con un delta o vértice que apunta al emisor.

${ }^{5}$ Forma gráfica que introduce el discurso del narrador y que tiene una función explicativa.
} 


\subsubsection{Blancos u objetivos}

Los blancos que más se repiten en las viñetas políticas de Forges con resolución de la incongruencia son José Luis Rodríguez Zapatero (18) (Figs. 8 y 13), Mariano Rajoy (17) (Figs. 8, 9 y 11), José María Aznar (8), viñetas que no tienen un blanco definido (7), la trama Gürtel (6), los políticos en general (5), los mercados (3) y el PSOE (3). Por otro lado, en las viñetas que apenas resuelven la incongruencia, los blancos que más se repiten son la trama Gürtel de nuevo (2) y aquellas viñetas que no tienen un blanco definido (2).

\subsection{Viñetas de contenido social}

\subsubsection{Oposición de marcos cognitivos}

En las viñetas que resuelven casi completamente la incongruencia (INC-RES), los tipos de oposiciones que más se repiten son del tipo binario: dinero / no dinero (12) (Fig. 16), real / no real (11), mundial / no mundial (11), actualidad / no actualidad (8), sano / enfermo (8), toros / no toros (7), crisis / no crisis (6), caro / barato (6), fútbol / no fútbol (5), trabajo / no trabajo (5) y rico / pobre (4). En las viñetas de contenido social que apenas resuelven la incongruencia (NON), los tipos de oposiciones no son relevantes ya que ninguno se repite.

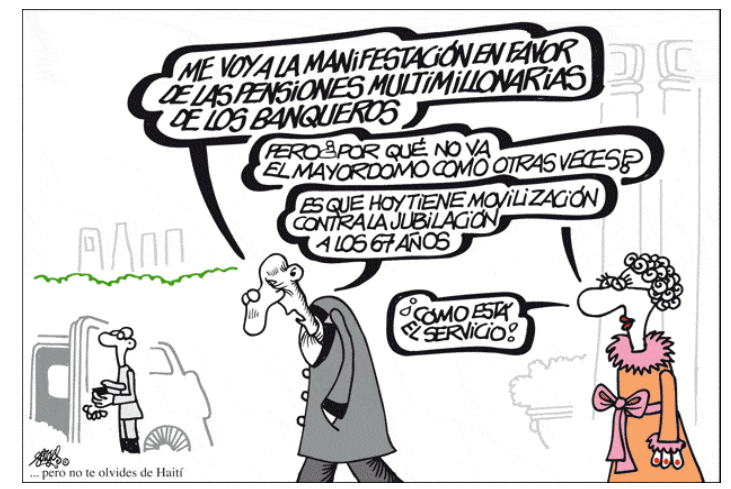

Fig. 16. El País, 23 febrero 2010. Reproducción autorizada por Forges

\subsubsection{Mecanismos lógicos}

Como se observa en la tabla (Fig. 17), en las viñetas que resuelven casi completamente la incongruencia (INC-RES), esta vez aparecen dos viñetas exclusivamente visua- 
les (PUN) (Figs. 1 y 7). Sin embargo, en todo el corpus de viñetas de contenido social no hay ninguna de falsa ambigüedad (TOM).

\begin{tabular}{|c|c|c|c|c|c|c|}
\hline \multicolumn{3}{|c|}{ INC-RES } & \multicolumn{3}{c|}{ NON } \\
\hline LMs & PUN & SEM & TOM & PUN & SEM & TOM \\
\hline Ambigüedad & & 8 & & & 2 & \\
\hline Analogía & 1 & 71 & & & 7 & \\
\hline Contradicción & & 44 & & & 4 & \\
\hline Exageración & & 84 & & & 8 & \\
\hline Cambio de roles & & 2 & & & & \\
\hline Juego de palabras & & 16 & & & 2 & \\
\hline Yuxtaposición & & 9 & & & & \\
\hline Sin LMs & 1 & 14 & & & 10 & \\
\hline
\end{tabular}

Fig. 17. Tabla de mecanismos lógicos en viñetas de contenido social

La mayoría de las viñetas es de tipo semántico y los mecanismos más utilizados son analogía (71), contradicción (44) y exageración (84) en las viñetas INC-RES, y analogía (7), exageración (8) y mecanismos lógicos no definidos (10) (Fig. 19) en las viñetas NON. La Figura 18 muestra la contradicción entre lo que expresa el locugrama y la expresión facial de los personajes dibujados. En la Figura 19, sin embargo, no existe mecanismo lógico definible ni se resuelve ninguna incongruencia.

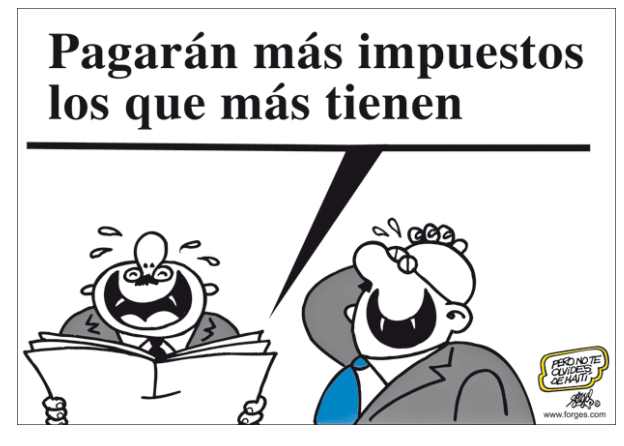

Fig. 18. El País, 21 mayo 2010. Reproducción autorizada por Forges

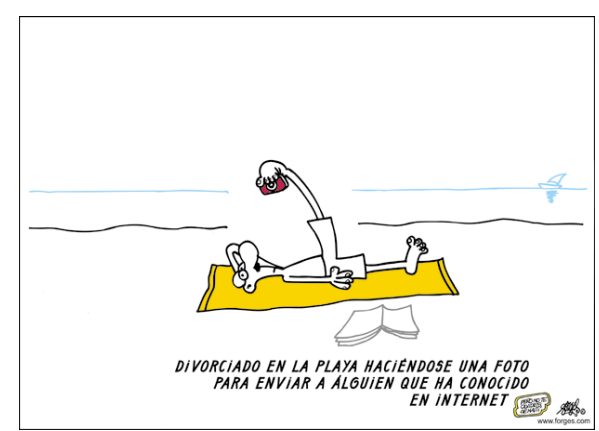

Fig. 19. El País, 6 agosto 2010. Reproducción autorizada por Forges

\subsubsection{Estrategias narrativas}

Como se aprecia en la tabla (Fig. 20), en las viñetas que resuelven la incongruencia predominan aquellas compuestas por una escena y globo (144) y, de nuevo, en las viñe- 
tas que apenas resuelven la incongruencia, la diferencia entre estas (14) y las que tienen una sola escena con apoyatura (11) es menor.

\begin{tabular}{|l|c|c|}
\hline \multicolumn{3}{|c|}{ ESTRATEGIAS NARRATIVAS } \\
\hline 1 escena con globlos & INC-RES & NON \\
\hline 1 escena con apoyaturas & 144 & 14 \\
\hline 1 escena con globos más apoyaturas & 21 & 11 \\
\hline 1 escena con título & 8 & 4 \\
\hline 1 escena con título más globos & 18 & 3 \\
\hline 1 escena con título más apoyaturas & 14 & 1 \\
\hline 1 escena con título más globos más apoyaturas & 2 & \\
\hline 1 escena sin palabras & 4 & \\
\hline 2 escenas con globos & 1 & \\
\hline 2 escenas con apoyaturas & 1 & \\
\hline 2 escenas más globos más apoyaturas & 1 & \\
\hline
\end{tabular}

Fig. 20. Tabla de estrategias narrativas en viñetas de contenido social

\subsubsection{Blancos u objetivos}

Los blancos que más se repiten en las viñetas de contenido social que resuelven casi completamente la incongruencia (INC-RES) son viñetas sin blanco definido (83) (Figs. 5,10 y 19), aficionados al fútbol (15) (Fig. 21), especuladores (11), bancos (9), aficionados a los toros (6), becarios (5), funcionarios (4), el Fondo Monetario Internacional (3) y los meteorólogos (3). Por otro lado, en las viñetas que apenas resuelven la incongruencia, la mayoría de los blancos no son definidos (17); Haití es también un foco de interés recurrente (3).

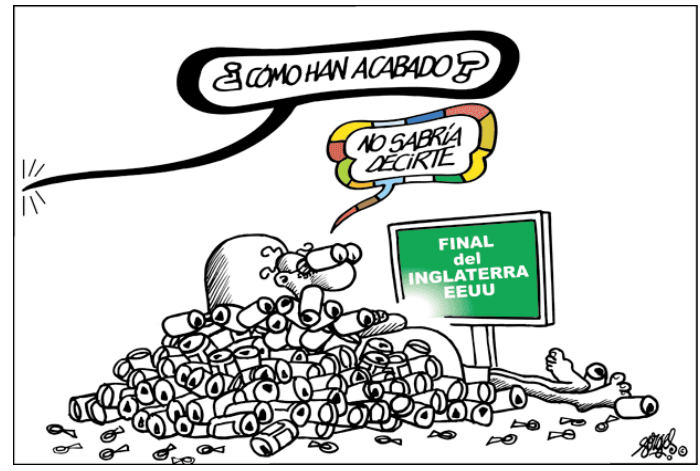

Fig. 21. El País, 13 junio 2010. Reproducción autorizada por Forges 


\section{Conclusiones}

El estudio realizado demuestra que los parámetros establecidos en la Teoría General del Humor Verbal son aplicables al humor gráfico. De los resultados del análisis del corpus seleccionado se pueden extraer conclusiones acerca de los mecanismos que emplea Forges para realizar su crítica o aportar su punto de vista dentro del panorama político y social actual. Antonio Fraguas es un autor comprometido con la realidad social y política actual, como revela la repetición de las oposiciones de marcos cognitivos y blancos relacionados con sucesos ocurridos entre los años 2010 y 2011. Sin embargo, predomina en su obra la viñeta de crítica social sobre la de carácter político. Son también mayoritarias las viñetas que resuelven casi por completo la incongruencia (332) sobre las que apenas la resuelven (42). Del mismo modo, las viñetas semánticas (368) priman sobre las visuales (2) y las de falsa ambigüedad (2).

Los mecanismos lógicos más utilizados por Forges para conseguir el efecto cómico en sus viñetas son la analogía, la contradicción y la exageración, aunque en las viñetas que apenas resuelven la incongruencia (NON) es recurrente el uso de mecanismos lógicos no definidos (en particular, en aquellas en las que un personaje sostiene un cartel con un mensaje reivindicativo). En cuanto a las estrategias narrativas utilizadas, predominan las viñetas con una escena o recuadro complementados por globos que integran gráficamente el texto de los diálogos o el pensamiento de los personajes en la estructura icónica de la viñeta. Sin embargo, en las viñetas de contenido político que apenas resuelven la incongruencia (NON) son más comunes las viñetas que integran apoyaturas explicativas.

A pesar de que la TGHV fue propuesta en principio para el análisis del humor verbal, en este artículo se ha demostrado que es perfectamente aplicable al análisis de las viñetas visuales y verbo-icónicas. En una viñeta multimodal es necesario identificar las distintas estrategias que el autor utiliza cuando se funden imagen y palabra en ese marco espacial. En las viñetas multimodales (escripto-icónicas), el efecto humorístico se produce cuando el receptor percibe la disonancia entre los elementos visuales y verbales del texto. En la mayoría de los pictogramas de Forges, existe una función de relevo o de interreferencia (Barthes, 1977); es decir, la imagen ayuda a interpretar el mensaje lingüístico. En ellas, los elementos lingüísticos y analógicos están en relación complementaria a la hora de transmitir un mensaje irónico. En las viñetas que solo contienen una pequeña apoyatura verbal (Fig. 6), esta cumple una función de anclaje con un claro valor irónico (Barthes, 1977); es decir, es el mensaje lingüístico el que da sentido al contenido de la imagen. Por último, las viñetas basadas exclusivamente en la imagen, sin elementos verbales, contienen siempre metáforas visuales (Figs. 1 y 7 ). 
Las viñetas que aparecen en las páginas editoriales de los periódicos permiten a los autores expresar su ideología, utilizando la ironía y la metáfora como estrategias subversivas para concienciar a los lectores de sucesos que podrían pasarles inadvertidos (El Refaie, 2005). A pesar de su aparente sencillez, como se ha demostrado en este artículo, la producción y percepción del discurso humorístico en las viñetas de prensa no es tarea fácil. Los humoristas gráficos emplean viñetas monomodales y viñetas multimodales para transmitir al lector su particular visión de la realidad política o social. En ambas se utiliza la imagen como recurso semiótico para producir un efecto cómico. Sin embargo, en el caso de las viñetas multimodales, el éxito del mensaje depende no solo del contenido pictográfico, sino también de la relación de dependencia que dicho contenido guarda con un elemento lingüístico, con una clara función de relevo o de anclaje.

Numerosos estudios han abordado la relación entre las viñetas de humor político y la lingüística cognitiva (Bergen, 2003): La Teoría de la Integración Conceptual (Conceptual Blending) (Faucconier y Turner, 2002), la Teoría de la Metáfora Conceptual (Lakoff y Johnson, 1980) y la Teoría de los Modelos Culturales (Holland y Quinn, 1987). Las investigaciones de Forceville (1996, 2006 y 2009) o de Juana Marín Arrese (2008) han analizado el papel que desempeñan mecanismos cognitivos como la metáfora y la metonimia en la creación e interpretación del humor en las viñetas de opinión.

La multimodalidad es, por tanto, un campo de estudio de creciente interés investigador. Aunque la TGHV es aplicable al estudio de las viñetas escripto-icónicas, queda un largo camino por recorrer en la comprensión del humor de textos intersemióticos. Quizá sea necesario, como proponen Kress y van Leeuwen (2006 [1996]), diseñar gramáticas dentro de los recursos semióticos multimodales, ya sean lingüísticos, visuales o sonoros. Un mayor conocimiento de las características del medio permitiría comprender mejor las relaciones de significado entre ambos códigos. Asimismo, sería interesante analizar la resemiotización de los fenómenos multimodales dependiendo de las prácticas sociales (O’Halloran, 2011), i.e., cómo cambia el significado a medida que el discurso alterna con distintos recursos semióticos. Tampoco debe olvidarse que las viñetas políticas son efímeras y que, por tanto, su comprensión puede ser parcial si se las escinde de su contexto original. Sobre la importancia del contexto, El Refaie (2009b) apuesta por un análisis de la viñeta política ubicada en la página de opinión en que aparece publicada en el periódico. 


\section{Referencias bibliográficas}

Attardo, S. (1991): Linguistic theories of humor. Berlín, Mouton de Gruyter.

Attardo, S. (2001): Humorous texts: A semantic and pragmatic analysis. Berlín/Nueva York, Mouton de Gruyter.

Attardo, S. (2006): “Cognitive linguistics and humor”, Humor: International Journal of Humor Research, 19 (3), págs. 341-362.

Attardo, S. y Raskin, V. (1991): "Script theory revis(it)ed: joke similarity and joke representation model”, Humor: International Journal of Humor Research, 4 (3-4), págs. 293-347.

Attardo, S., Hempelmann, C. F. y DiMaio, S. (2002): "Script oppositions and logical mechanisms: modeling incongruities and their resolutions", Humor: International Journal of Humor Research, 15, págs. 3-46.

Barthes, R. (1977): Image, music and text. Londres, Fontana.

Bergen, B. (2003): "To awaken a sleeping giant. Cognition and culture in September 11 political cartoons", Language, Culture, and Mind, págs. 23-35.

Bergson, H. (1911 [1899]): Laughter: An essay on the meaning of the comic. Nueva York, Macmillan.

El Refaie, E. (2003): "Understanding visual metaphor: The example of newspaper cartoons”, Visual Communication, 2 (1), págs. 75-96.

El Refaie, E. (2005): "Our purebred ethnic compatriots: irony in newspaper journalism", Journal of Pragmatics, 37, págs. 781-797.

El Refaie, E. (2009a): "Multiliteracies: How readers interpret political cartoons", Revista Visual Comunication, 2 (8), págs. 181-205.

El Refaie, E. (2009b): "What makes us laugh? Verbo-visual humour in newspaper cartoons". En Ventola, E. y Moya Guijarro, A. J. (eds.): The world told and the world shown: Multisemiotic issues. Hampshire, Palgrave Mcmillan, págs. 75-90.

El Refaie, E. y Hörschelmann, K. (2010): "Young people's readings of a political cartoon and the concept of multimodal literacy", Revista Discourse: Studies in the Cultural Politics of Education, 2 (31), págs. 195-207.

Fauconnier, G, y Turner, M. (2002): The way we think: Conceptual blending and the mind's hidden complexities. New York, Basic Books.

Forceville, G. (1996): Pictorial metaphor in advertising. Londres/Nueva York, Routledge.

Forceville, C. (2006): "Non-verbal and multimodal metaphor in a cognitivist framework: agendas for research". En Kristiansen, G., Achard, M., Dirven, R. y Ruiz de Mendoza, F. (eds.): Cognitive linguistics: Current applications and future perspectives. Berlín/Nueva York, Mouton de Gruyter, págs. 379-402. 
Forceville, C. y Urios-Aparisi, E. (2009): Multimodal metaphor. Berlín y Nueva York, Mouton de Gruyter.

Freud, S. (1991 [1905]): Jokes and their relation to the unconscious. Harmondsworth, Penguin.

Galán Rodríguez, M. (1994): "La creatividad léxica: los neologismos en A. Fraguas de Pablo (Forges)". Disponible en: http://dialnet.unirioja.es/servlet/articulo?codigo =58814. (Acceso: 29.03.2013).

Grice, H. P. (1975): "Logic and conversation". En Cole, P. y Morgan, J. (eds.): Syntax and semantics, vol. 3. Nueva York, Academic Press, págs. 41-58.

Halliday, M. (1985): An introduction to functional grammar. Londres, Edward Arnold.

Hempelmann, C. y Ruch, W. (2005): "3 WD meets GTVH: breaking the ground for interdisciplinary humor research", Humor: International Journal of Humor Research, 18 (4), págs. 353-387.

Hobbes, T. (1994 [1668]): Leviathan. Indianápolis, Hackett.

Holland, D y Quinn, N., (eds) (1987): Cultural models in language and thought. Cambridge, Cambridge University Press

Kant, I. (1790): Critique of judgement. Guyer, P. (trans.) Cambridge, Cambridge University Press, 2000.

Kress, G. y Van Leeuwen, T. (2001): Multimodal discourse - The modes and media of contemporary communication. Londres, Edward Arnold.

Kress, G. y Van Leeuwen, T. (2006 [1996]): Reading images: The grammar of visual design. Londres, Routledge.

Lakoff, G. y Johnson, M. (1980): Metaphors we live by. Chicago, The University of Chicago Press.

Lakoff, G. (1987): Women, fire and dangerous things: What categories reveal about the mind. Chicago y Londres, University of Chicago Press.

Leech, G. (1983): Principles of Pragmatics. Londres, Longman.

Marín Arrese, J. I. (2008): "Cognition and culture in political cartoons", Intercultural Pragmatics, 1 (5), págs. 1-18.

Moya Guijarro, A. J. y Pinar Sanz, M. J. (2009): “On interaction of image and verbal text in a picture book. A multimodal and systemic fuctional study". En Ventola, E. y Moya Guijarro, A. J. (eds.): The world told and the world shown: Multisemiotic issues. Hampshire, Palgrave Mcmillan, págs. 107-124.

O'Halloran, K. (2011): "Multimodal discourse analysis". En Hyland, K. Paltridge, B. (eds): Companion to discourse, Londres y Nueva York, Continuum, págs. 120-137.

Ortiz Díaz-Guerra, M.J. (2010): “Teoría integrada de la metáfora visual”, Comunicación y Sociedad, XXIII, 2, págs. 97-125. 
Paolillo, J. (1998): “Gary Larson's Far Side: nonsense? nonsense!”, Humor: International Journal of Humor Research, 11, págs. 261-290.

Raskin, V. (1985): Semantic mechanisms of humor. Dordrecht, D. Reidel.

Ruch, W. (1992): "Assessment of appreciation of humor: studies with the 3 WD humor test". En Butcher, J. N. y Spielberger, C. D. (eds.): Advances in personality assessment, vol. 9. Hillsdale, NJ, Erlbaum, págs. 27-75.

Ruiz Gurillo, L. (2012): La lingüística del humor en español. Madrid, Arco/Libros.

Samson, A. (2008): Cognitive and neural humor processing: The influence of structural stimulus properties and theory of mind. Tesis doctoral inédita. Universidad de Friburgo (Suiza).

Schank, R. y Abelson, R. (1977): Scripts, plans, goals and understanding. Nueva York, Wiley.

Schopenhauer, A. (1891 [1818]): "On the theory of the ludicrous". En Schopenhauer, A. (ed.): The world as will and idea, vol. 2. Londres, Kegan Paul, Trench, Trübner and Co, págs. 270-284.

Spencer, H. (1911): “On the physiology of laughter", Essays on Education, Etc., Londres, Dent, págs. 298-309.

Sperber, D. y Wilson, D. (1986): Relevance: Communication and cognition. Oxford, Blackwell.

Vigara Tauste, A. M. (2004): "Podréis quitarme todo, menos el miedo... El humor y su(s) sentido(s) en el acto de la comunicación”, Exit: Imagen y Cultura, 13, págs. 94-108.

Yus, F. (1995): "La significación social de las máximas de Grice: el caso del cómic alternativo ingles", Revista Canaria de Estudios Ingleses, 30-31, págs. 109-128.

Yus, F. (2003): "Humor and the search for relevance", Journal of Pragmatics, 35, págs. $1295-1331$. 